\title{
Low Doses of Ionizing Radiation as a Treatment for Alzheimer's Disease: A Pilot Study
}

\author{
Jerry M. Cuttler ${ }^{\mathrm{a}}$, Eslam Abdellah ${ }^{\mathrm{b}}$, Yael Goldberg ${ }^{\mathrm{b}}$, Sarmad Al-Shamaa ${ }^{\mathrm{b}}$, Sean P. Symons ${ }^{\mathrm{c}, \mathrm{d}, \mathrm{e}}$, \\ Sandra E. Black ${ }^{\mathrm{e}, \mathrm{f}, \mathrm{g}}$ and Morris Freedman ${ }^{\mathrm{b}, \mathrm{g}, \mathrm{h}, \mathrm{i}, *}$ \\ ${ }^{a}$ Cuttler \& Associates, Vaughan, ON, Canada \\ ${ }^{\mathrm{b}}$ Baycrest Health Sciences, Toronto, ON, Canada \\ ${ }^{\mathrm{c}}$ Departments of Medical Imaging and Otolaryngology-Head and Neck Surgery, University of Toronto, \\ Toronto, ON, Canada \\ ${ }^{\mathrm{d}}$ Department of Medical Imaging, Sunnybrook Health Sciences Centre, Toronto, ON, Canada \\ ${ }^{\mathrm{e}}$ Hurvitz Brain Sciences Research Program, Sunnybrook Research Institute, Toronto, ON, Canada \\ ${ }^{\mathrm{f}}$ Department of Medicine (Neurology), Sunnybrook Health Sciences Centre, Toronto, ON, Canada \\ $\mathrm{g}^{\mathrm{D}}$ Department of Medicine (Neurology), University of Toronto, ON, Canada \\ ${ }^{\mathrm{h}}$ Rotman Research Institute of Baycrest Centre, Toronto, ON, Canada \\ ${ }^{\mathrm{i}}$ Department of Medicine (Neurology), Mt. Sinai Hospital, Toronto, ON, Canada
}

Handling Associate Editor: Amos Korczyn

Accepted 18 January 2021

Pre-press 23 February 2021

\begin{abstract}
.
Background: In 2015, a patient in hospice with Alzheimer's disease (AD) was treated with ionizing radiation to her brain using repeated CT scans. Improvement in cognition, speech, movement, and appetite was observed. These improvements were so momentous that she was discharged from the hospice to a long-term care home. Based on this case, we conducted a pilot clinical trial to examine the effect of low-dose ionizing radiation (LDIR) in severe AD.

Objective: To determine whether the previously reported benefits of LDIR in a single case with AD could be observed again in other cases with $\mathrm{AD}$ when the same treatments are given.

Methods: In this single-arm study, four patients were treated with three consecutive treatments of LDIR, each spaced two weeks apart. Qualitative changes in communication and behavior with close relatives were observed and recorded. Quantitative measures of cognition and behavior were administered pre and post LDIR treatments.

Results: Minor improvements on quantitative measures were noted in three of the four patients following treatment. However, the qualitative observations of cognition and behavior suggested remarkable improvements within days post-treatment, including greater overall alertness. One patient showed no change.

Conclusion: LDIR may be a promising, albeit controversial therapy for AD. Trials of patients with less severe AD, doubleblind and placebo-controlled, should be carried out to determine the benefits of LDIR. Quantitative measures are needed that are sensitive to the remarkable changes induced by LDIR, such as biological markers of oxidative stress that are associated with AD.
\end{abstract}

Keywords: Adaptive protection systems, Alzheimer's disease, low-dose ionizing radiation, oxidative damage, therapy

\footnotetext{
${ }^{*}$ Correspondence to: Morris Freedman, MD, FRCPC, Baycrest, Brain Health Complex, Rm 656, 3560 Bathurst Street, Toronto,
}

Ontario M6A 2E1, Canada. Tel.: +1 4167582500 /Ext. 2400; Fax: +1416 785 2484; E-mail: mfreedman@ baycrest.org. 


\section{INTRODUCTION}

Alzheimer's disease (AD) is a neurodegenerative disorder that primarily affects older adults. It accounts for more than $50 \%$ of the cases of dementia and is one of the leading sources of morbidity and mortality in the aging population. While treatments are available that can ameliorate some symptoms of the illness, there is no cure or disease-modifying therapy currently available, and the disease inevitably progresses in all patients. The survival after diagnosis ranges from 3 to 20 years, with an average life expectancy of 8 to 10 years. Patients with advanced AD are admitted to hospice for palliative care as their endof-life approaches. Because the changes in the brain are associated with the accumulation of amyloid- $\beta$ plaques and tau protein, many clinical trials have been evaluating anti-amyloid therapies. However, autopsy data suggest that symptomatic AD will not occur in every patient with amyloid in the brain [1].

The primary goal of a therapy for old adults with $\mathrm{AD}$ should be to improve the quality of their lives by optimizing their well-being, staying brain health, and restoring communication with family and friends to avoid social isolation, loneliness, and under stimulation. Old adults should be able to recognize their spouse, children, and grandchildren.

A recent review article made a strong case to try radiation therapy ( $\mathrm{RT}$ ) for $\mathrm{AD}$, based on its history of success in treating systemic amyloidosis and the preclinical studies carried out on a transgenic murine model [2]. At this time, four clinical trials are registered on the application of low doses of ionizing radiation (LDIR), 2 Gy each, to treat systemic amyloid deposits and chronic inflammatory disease using oncological RT [3-8]. The results of recent preclinical studies [9] suggested that this therapy can modulate the polarization of microglia; LDIR directly induced phenotype switching in the brain from proinflammatory M1 to anti-inflammatory M2.

The single-arm pilot clinical trial described in this paper is different from the trials that remove amyloid plaque. It was conducted to repeat treatments of much lower doses of ionizing radiation in severe $\mathrm{AD}$, after a case treated in 2015 reported remarkable increases in cognition, speech, movement, and appetite following standard CT scans of the brain. Each scan, prescribed by the patient's physician, delivered a dose of $40 \mathrm{mGy}$ within $10 \mathrm{~s}$. Two were given on July 23, and surprising changes were observed by the caregiver on the next day. Additional scans were given on August 6, August 20, and October 1 to amplify and prolong the effect. The improvements were so momentous that the patient was moved on November 20 from hospice to a home for seniors with a stimulating day program [10]. The 81-year-old woman had been examined on May 21, 2015 by a neuropsychologist who found her "completely nonresponsive." After the treatments, a neuropsychologist examined her on October 12 and re-examined her on April 15,2016 . He noted that she "was able to give simple verbal responses to direct, simple questions. Not all of her responses were related to the direct questions, but she seemed to be reacting appropriately to the prosody and nonverbal cues of those around her. This represents some improvement from October 12, 2015, when I last saw her [11]." She received a "booster" treatment on February 24, 2016 and others in 2016 and 2017, to enhance and prolong the induced changes. Also, living in a home for seniors with a stimulating day program likely contributed to her improved state. However, her condition began to decline and on March 6, 2017 she was returned to hospice care [12]. She died on May 18, 2018.

The objective of this single-arm study was to determine whether the reported benefits of LDIR therapy in a single case with severe AD [10-12] could be observed again in others with severe $\mathrm{AD}$ when the same treatments are repeated. Data on qualitative observations of communication and behavior by close relatives were collected; quantitative measures of cognition and behavior were administered pre and post LDIR treatments.

LDIR therapy is controversial because it is generally accepted that ionizing radiation is a significant cause of DNA mutations and increases cancer risk. Most people are unaware that the rate of DNA damage due to natural background radiation is negligible compared to the rate of DNA alterations caused by the endogenous production of reactive oxygen species [13]. "Oxidative stress is a common denominator in the pathology of neurodegenerative disorders such as Alzheimer disease, Parkinson's disease, Huntington's disease, amyotrophic lateral sclerosis, and multiple sclerosis, as well as in ischemic and traumatic brain injury. The brain is highly vulnerable to oxidative damage due to its high metabolic demand. However, therapies attempting to scavenge free radicals have shown little success [14]."

Organisms require redox cell-signaling agents in order to function, and there are multiple sources of these vital agents [15-18]. To cope with oxidative and all other causes of damage, all organisms have enormously powerful innate adaptive protection 


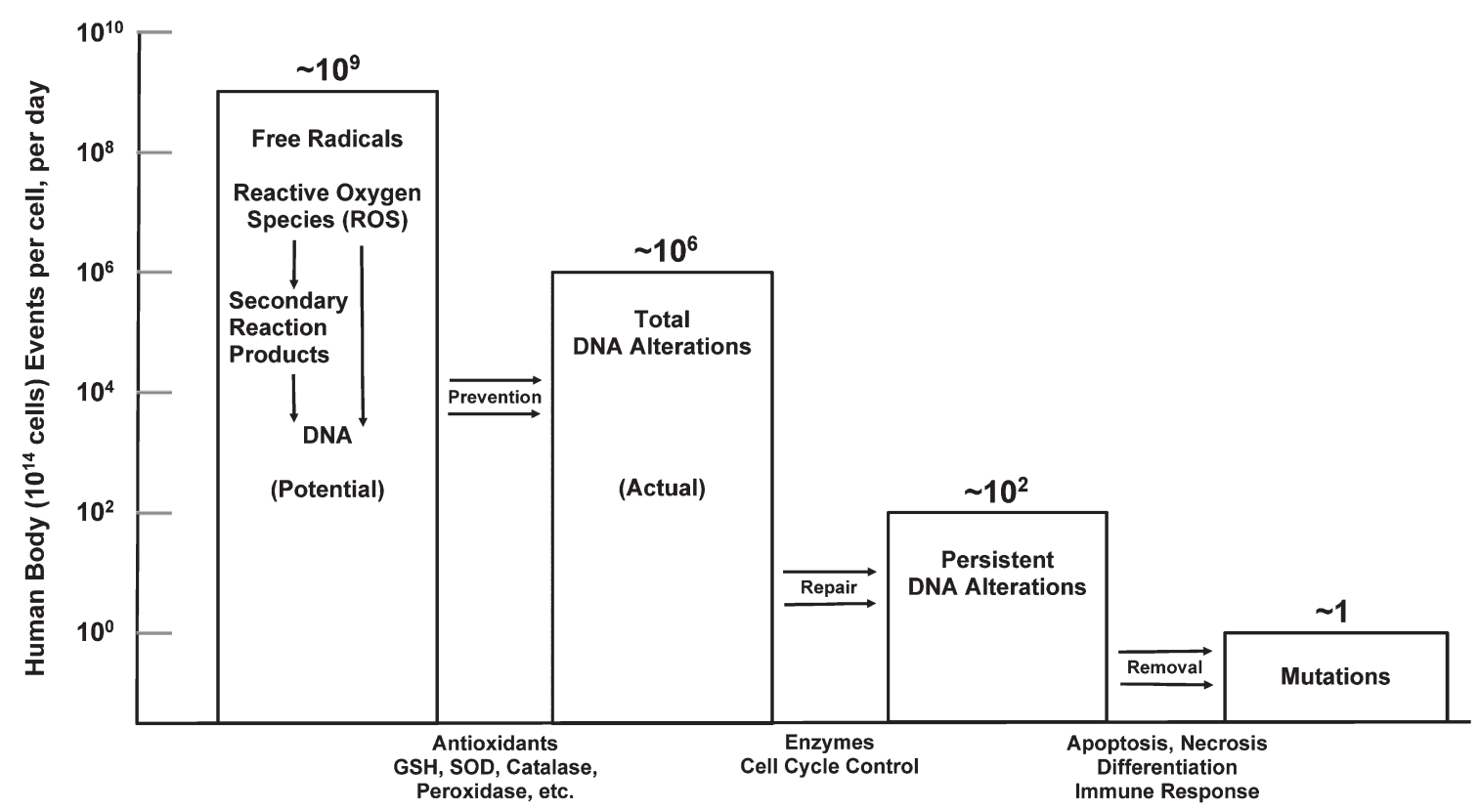

Natural Defenses

Fig. 1. Natural defenses act against endogenous DNA damage. A $100 \mathrm{~kg}$ person contains about $10^{14}$ cells (avg. cell wt. $\sim 10^{-9} \mathrm{~g}$ ). Free radical production would cause $\sim 10^{9}$ DNA alterations per cell per day; however, antioxidant production lowers the actual rate to $\sim 10^{6} \mathrm{DNA}$ alterations per cell per day. The damage-repair defense lowers the incidence of persistent DNA alterations to $\sim 10^{2}$ per cell per day, and the damaged-cell removal defence results in the natural occurrence of one mutation per cell per day. (The ratio of metabolic DNA damage to radiation-induced DNA damage by $0.1 \mathrm{cGy} /$ year natural background radiation is about 10 million.) Reprinted with permission from Pollycove M, Feinendegen LE [13], ( 2003 SAGE Publications and adapted for this publication.

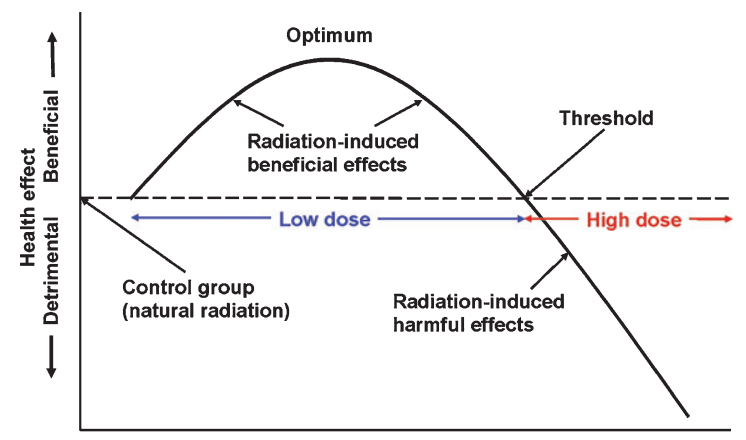

Absorbed radiation dose or dose-rate

Fig. 2. The biphasic dose-response model and the definition of a low dose of radiation. Reprinted with permission from Cuttler JM [20], (C) 2020 SAGE Publications and adapted for this publication. Reference [35], Fig. 1 suggests that optimal radiation-induced stimulation of the protection systems occurs when the dose is between 0.1 to $0.5 \mathrm{~Gy}$. The threshold for adverse effects due to an acute exposure (dose fraction) of the brain is about $3 \mathrm{~Gy}$.

systems (APS), which produce antioxidant enzymes, repair DNA breaks and other molecular damage, kill and scavenge unrepaired cells, and restore good health (Fig. 1) [13]. However, APS potency progressively weakens with age, becoming less capable in remediating the damaging effects of ongoing oxidative distress [19].

A brief exposure to ionizing radiation damages biomolecules, including DNA, directly by "hits" on atoms and indirectly by the reactive oxygen species from radiolysis of water. The burst of damage events triggers an APS response that is biphasic, as shown in Fig. 2. A high dose, above the threshold for the onset of lasting harmful effects, inhibits or damages the APS. Based on radiotherapy for cancer, this threshold is about $3 \mathrm{~Gy}$. On the other hand, a low dose of radiation, i.e., below $3 \mathrm{~Gy}$, stimulates the APS to overrespond [20]. After a low dose, there is remediation not only of the radiation-induced damage but also damage resulting from both endogenous and exogenous factors such as natural oxidative aging, pathogens, toxins, and injuries. There is an immediate response and a delayed response because of cellular signaling [19, 21].

A recent study demonstrated X-ray-induced restoration of cognitive performance in transgenic mice deficient of DNA glycosylases [22]. This genetic change, which impaired the removal of oxidative damage, caused low spatial learning and poor memory. 
After a 0.5 Gy dose of X-rays, their early-phase learning ability and memory equaled that of normal mice for weeks.

In this study, LDIR therapy of AD is based on the hypotheses that oxidative stress is a major factor in the development of AD and that stimulation of the APS in the brain by the low radiation dose of a CT scan will reverse or delay progression of this disorder. The LDIR doses that were employed in this study are the same as those that were administered in 2015 [10].

\section{METHODS}

The study was approved by the Baycrest Research Ethics Board (REB) and Sunnybrook Health Sciences Centre REB. The trial was registered in July 2018 [23]. Informed consent was obtained from substitute decision makers. Participants received standard CT brain scans at Sunnybrook, each a CTDI ${ }_{\mathrm{vol}}$ dose of $40 \mathrm{mGy}$. (CTDI ${ }_{\mathrm{vol}}$ is volume computed tomography dose index [24].) The investigators judged that repeating the initial three treatments of the case report [10] would be adequate to determine whether the previously reported benefits could be observed again. The first was a double scan because the originally reported case received a second scan during the same treatment session after moving during the first one.

CT was performed on a General Electric LightSpeed VCT 64 detector scanner. Helical mode was used. Slice thickness was $2.5 \mathrm{~mm}$. Detector coverage was $40.0 \mathrm{~mm}$. Pitch was 0.969:1. Speed was $19.37 \mathrm{~mm}$ per rotation. Rotation time was 1.0 second; $\mathrm{kV}$ was 120 . The automatic $\mathrm{mA}$ selection setting was utilized.

We studied four participants who were residents in long-term care at Baycrest Health Sciences and who had advanced dementia (MMSE $<12$; ages 8190; males/females $=3 / 1$ ), presumed to be primarily due to AD [25]. All were clinically stable for at least three months. Those taking a cholinesterase inhibitor and/or memantine were on a stable dose for at least 60 days prior to participation in the study. Exclusion criteria were history of malignancy, radiotherapy, neurological disorder other than $\mathrm{AD}$, stroke, and active major depression, bipolar affective disorder, or psychosis within the previous 90 days. None of the participants were receiving experimental treatments.

As in the previous case report, qualitative data on patient communication and interaction with family members and caregivers were obtained by requesting verbal and written feedback, and by careful observation during visits when they were present with each patient. These data were reproduced verbatim in study documents.

In addition, three quantitative outcome measures were employed in this study to assess neurocognitive capacity, behavioral symptoms, and functional ability. The Severe Impairment Battery (SIB) [26] was chosen to measure cognition because it is the only available tool designed to "characterize the neuropsychological profile of severely demented patients" who are otherwise unable to engage in such testing due to impairment severity. The Cohen-Mansfield Agitation Index (CMAI) [27] was chosen to measure behavioral symptoms of dementia because it is considered the gold standard in assessing the frequency of responsive behaviors in the elderly. It was developed for use in nursing homes. Functional status was evaluated by the Alzheimer Disease Functional Assessment and Change Scale (ADFACS) [28], a tool designed to assess functional capacity in individuals with various stages of dementia. In our study population, we expected significant limitations in ability to carry out both instrumental activities of daily living (e.g., medication management), and basic activities of daily living (e.g., personal grooming and toileting) due to cognitive deficits resulting from advanced disease progression. The ADFACS was specifically chosen because it measures functional capacity in both areas, in a 16-item informant-based questionnaire. It is widely used in clinical research and has good diagnostic and concurrent validity [28].

The ADFACS and SIB instruments were administered by neurology fellows before the treatments and for eight weeks after the final treatment. The CMAI was administered or supervised by a neuropsychologist. The neurology fellows obtained and maintained all the data.

Table 1 lists the dates and doses of the LDIR treatments.

Table 1

LDIR treatment dates (2019) and CTDI $_{\text {vol }}$ doses (mGy)

\begin{tabular}{lccc}
\hline & $\begin{array}{c}\text { 1st } \\
\text { treatment }\end{array}$ & $\begin{array}{c}\text { 2nd } \\
\text { treatment }\end{array}$ & $\begin{array}{c}\text { 3rd } \\
\text { treatment }\end{array}$ \\
\hline Case 1 $(88 \mathrm{y})$ & Feb 8 & Feb 22 & Mar 8 \\
Dose & 81.0 & 41.0 & 43.0 \\
Case 2 $(90 \mathrm{y})$ & Jul 16 & Jul 30 & Aug 13 \\
Dose & 89.0 & 46.0 & 40.0 \\
Case 3 $(84 \mathrm{y})$ & Sep 10 & Sep 24 & Oct 8 \\
Dose & 79.0 & 40.0 & 43.0 \\
Case 4 $(82 \mathrm{y})$ & Dec 17 & Dec 31 & Jan 14 \\
Dose & 80.0 & 40.3 & 40.4 \\
\hline
\end{tabular}




\section{RESULTS}

Table 2 shows the pre- and post-treatment scores on the outcome measures. Supplementary Table 1 lists the CMAI assessment scores for the four participants.
Case 1 (88-year-old male, baseline MMSE 5/30)

He ate without assistance, watched TV, and took frequent naps. Speech was fluent but tended to be unrelated to the topic and was marked by confabulation.

Table 2

Pre- and post-treatment scores on the outcome measures

\begin{tabular}{|c|c|c|c|c|c|c|c|}
\hline \multirow{2}{*}{$\begin{array}{l}\text { Treatment } \\
\text { date (2019) }\end{array}$} & \multirow{2}{*}{$\begin{array}{c}\text { Evaluation } \\
\text { date }\end{array}$} & \multirow[t]{2}{*}{ SIB } & \multirow{2}{*}{$\begin{array}{c}\text { CMAI } \\
\text { deviation } \\
\text { from } \\
\text { baseline }\end{array}$} & \multirow{2}{*}{$\begin{array}{l}\text { Behavioral } \\
\text { changes } \\
\text { observed } \\
\text { on CMAI }\end{array}$} & \multicolumn{3}{|c|}{ ADFACS } \\
\hline & & & & & IADL \% & ADL \% & Total \% \\
\hline \multicolumn{8}{|l|}{ Case 1} \\
\hline & Feb 05 & 21 & Baseline & & 22.5 & 60 & 39 \\
\hline \multirow[t]{2}{*}{ Feb 8} & Feb 12 & 22 & No data & No data & 22.5 & 60 & 39 \\
\hline & Feb 20 & 23 & Yes & $\begin{array}{l}\text { Decrease in } \\
\text { restlessness }\end{array}$ & 22.5 & 60 & 39 \\
\hline Feb 22 & Feb 25 & 31 & No data & No data & & No data & \\
\hline Mar 8 & Mar 11 & 13 & No data & No data & & No data & \\
\hline \multicolumn{8}{|l|}{ Case 2} \\
\hline & Jul 15 & 0 & Baseline & & 0 & 20 & 10 \\
\hline \multirow[t]{3}{*}{ Jul 16} & Jul 17 & 0 & No & None & 0 & 20 & 10 \\
\hline & Jul 23 & 0 & No & None & 0 & 20 & 10 \\
\hline & Jul 30 & 0 & No & None & 0 & 20 & 10 \\
\hline \multirow[t]{2}{*}{ Jul 30} & Aug 06 & 0 & No & None & 0 & 20 & 10 \\
\hline & Aug 13 & 0 & No & None & 0 & 20 & 10 \\
\hline \multirow[t]{4}{*}{ Aug 13} & Aug 20 & 0 & No & None & 0 & 20 & 10 \\
\hline & Aug 27 & 0 & No & None & 0 & 20 & 10 \\
\hline & Sep 03 & 0 & No & None & 0 & 20 & 10 \\
\hline & Sep 09 & 0 & No & None & 0 & 20 & 10 \\
\hline \multicolumn{8}{|l|}{ Case 3} \\
\hline & Sep 09 & 2 & Baseline & & 0 & 37 & 15.8 \\
\hline \multirow[t]{2}{*}{ Sep 10} & Sep 11 & 2 & No & None & 0 & 37 & 15.8 \\
\hline & Sep 16 & 2 & No & None & 0 & 37 & 15.8 \\
\hline \multirow[t]{3}{*}{ Sep 24} & Sep 25 & 2 & No & None & 0 & 37 & 15.8 \\
\hline & Oct 01 & 2 & No & None & 0 & 37 & 15.8 \\
\hline & Oct 08 & 2 & No & None & 0 & 37 & 15.8 \\
\hline \multirow[t]{4}{*}{ Oct 8} & Oct 16 & 3 & Yes & $\begin{array}{l}\text { Increased } \\
\text { physical } \\
\text { aggression } \\
\text { towards } \\
\text { himself (i.e., } \\
\text { self-biting) }\end{array}$ & 0 & 37 & 15.8 \\
\hline & Oct 22 & 2 & No & None & 0 & 37 & 15.8 \\
\hline & Oct 30 & 2 & No & None & 0 & 37 & 15.8 \\
\hline & Nov 07 & 2 & No & None & 0 & 37 & 15.8 \\
\hline \multicolumn{8}{|l|}{ Case 4} \\
\hline & Dec 16 & 5 & Baseline & & 5 & 26.7 & 14.3 \\
\hline \multirow[t]{2}{*}{ Dec 17} & Dec 18 & 4 & No & None & 5 & 26.7 & 14.3 \\
\hline & Dec 23 & 4 & No & None & 5 & 26.7 & 14.3 \\
\hline \multirow[t]{3}{*}{ Dec 31} & Jan 02 & 4 & No & None & 5 & 26.7 & 14.3 \\
\hline & Jan 07 & 4 & No & None & 5 & 26.7 & 14.3 \\
\hline & Jan 13 & 6 & No & None & 5 & 30 & 15.7 \\
\hline \multirow[t]{4}{*}{ Jan 14} & Jan 20 & 5 & No & None & 5 & 30 & 15.7 \\
\hline & Jan 27 & 4 & No & None & 5 & 26.7 & 14.3 \\
\hline & Feb 03 & 5 & No & None & 5 & 26.7 & 14.3 \\
\hline & Feb 10 & 4 & No & None & 5 & 26.7 & 14.3 \\
\hline
\end{tabular}

SIB, Severe Impairment Battery [25]; CMAI, Cohen-Mansfield Agitation Index [26]; ADFACS, Alzheimer Disease Functional Assessment and Change Scale [27]; IADL, Instrumental Activities of Daily Living; ADL, Basic Activities of Daily Living. 
This pattern of behavior did not change during the study.

There were no changes in the ADFACS scores. However, he became less restless after the first treatment, as reflected in the CMAI score. There was improvement in the SIB score after the second treatment, but the score dropped below baseline two weeks later.

Qualitatively, the family reported that he was much more alert after the LDIR treatments. The evening after the first treatment, his son was surprised to see enthusiastic participation in the Sabbath service. The following week, he walked holding his son's hand and had improved balance. He recognized his daughter immediately upon her arrival and was more responsive to her dialogue and requests. He was able to get into his wheelchair easily and put his feet on the footrests when asked to do so. He was able to speak with his granddaughter on the phone and could address her by name. At a concert, he sang to the rhythm and applauded appropriately. He remarked on the hospital renovations underway and commented on the accumulation of snow outside. After the second treatment, his son-in-law said that his conversation was more rational. He also read signs aloud that were posted on the wall. The family was surprised and pleased with his improvement.

\section{Case 2 (90-year-old male; baseline MMSE 0/30)}

He could not weight-bear and was dependent on a mechanical lift for transfers to and from his wheelchair. He required full assistance with feeding and usually fell asleep between each spoonful. His caregiver often instructed him to open his mouth, chew, and swallow. Sometimes, he was alert and ate all his food quickly. After meals, he usually slept. When alert, he looked at his surroundings and at people going by. He complied with his caregiver's requests. This pattern of behavior did not change during the study.

There were no changes on the three quantitative outcome measures. Moreover, the family did not note any qualitative improvements.

\section{Case 3 (84-year-old male, baseline MMSE 0/30)}

He was non-verbal most of the time and typically required full assistance with feeding. He could not walk. He would leaf through magazines and flip a deck of cards.

There were no changes in the ADFACS score. On the CMAI, there was increased aggression toward himself, i.e., self-biting, noted on the third assessment.
There was no change in the SIB score, except on one day when he wrote his name.

Qualitatively, there were occasions when he was alert and cooperative. On the day after the first treatment, his daughter gave a very positive report. She noted that he recognized and smiled at his wife, which was unusual for him. When asked what he wanted for supper, he said "chicken" and had a big smile on his face. The following day his daughter noted that he seemed more alert, listened better, and nodded appropriately during conversation. He fed himself independently and posed for a photo. She said, "I haven't seen him hold the bowl and use the other hand to feed himself so well." He also did up buttons on his shirt when instructed to do so and followed simple verbal commands such as kicking his daughter's hand with his foot. He also seemed to be "more himself" at times and initiated communication. When he saw his reflection in the window, he fixed his hair accordingly.

Five days after the first treatment, his daughter noted, "I had an amazing visit with my dad this evening. I'm speechless from last night. He was excited to see me - he spoke to me right away and gave me multiple kisses - real kisses like years ago. He was clapping his hands to the music. My mom agreed it's been years since he has done this. Everyone is amazed. My husband was there with me as a witness." When his daughter asked him if he wanted to go for a walk, with her pushing his wheelchair, he said, "Not now." She said that if he ever said anything previously, it would be "no." After he agreed to let her push him in his wheelchair, he immediately noticed that she forgot her purse. He looked at her and pointed strongly at her purse.

Five days after the second treatment, he showed delight at seeing his wife. When his son arrived, he recognized him instantly and reached out. His smiling, tearful face expressed great joy as they hugged. Then he gave an expression of pain as he communicated his awareness that he was losing cognition and appeared terribly upset about this. His daughter said, “... we see real improvement." Six weeks after the third and final treatment, his family requested additional double-scan treatments after observing a large decline in that improvement.

\section{Case 4 (82-year-old female; baseline MMSE $0 / 30)$}

She required assistance with feeding and showering. After two hip replacement operations, she could 
walk a short distance with assistance. She strongly resisted traveling for the first treatment, so she was given a sedative prior to leaving for the second treatment. During the trip for her third treatment, she cooperated and was talkative.

No quantitative changes were observed after the first two treatment sessions. However, she improved just before her third treatment, becoming calm, pleasant, and cooperative. Her functional status on the ADFACS improved from $14.3 \%$ to $15.7 \%$. The improvement was in basic activities of daily living (ADLs), from $26.7 \%$ to $30 \%$, without change in instrumental activities of daily living (IDALs). There was no change in her CMAI and only a slight improvement in the SIB from 4-5 to 6.

One day after the first treatment, her oldest son found her more responsive and engaged, including during a cellphone conversation. She answered quickly and was more alert and attentive. She smiled and said hello to another son when he visited on the following day. She usually didn't respond when she saw him. A day later, another son reported, "When I said hello, she looked at me and said, 'Hello dear.' She hadn't said this to me in years!"

Five days after the treatment, at a holiday concert, she spoke with two of her sons and daughter in short sentences in response to their remarks and questions. She listened and nodded as relatives, friends, and many events were mentioned. They reminisced about how she met her husband, their life in Toronto, the births of her six children, and the family inn at a summer resort. While listening to the reminiscing, she said jokingly, "Don't give away all the family secrets." She cried a few times. When asked whether she was in pain or upset, she replied, "No, I'm very happy." She laughed when asked whether she was ready to dance, as her legs moved to the rhythm of the music. She expressed gratitude for her recovery.

One week after the first treatment, she told her sister on the phone that she loved her. On another family visit just before her second treatment, she sat between her sister and daughter and talked. The family said she was still more alert than usual and in a good mood. Her sister said she was much more responsive than months before. It was normally difficult for her to stand and leave the table but today she stood and left the table without assistance when asked. Days after her third treatment, she answered direct questions and laughed. She enjoyed the concert but protested when a friend got up to leave early. Two months after her final treatment, several caregivers reported that she was still improved over her original condition.

\section{DISCUSSION}

Four participants with advanced AD were treated with LDIR. Severe cases who were clinically stable were selected for this small, single arm trial with the objective of repeating the case of a patient with advanced AD [10]. Each participant received three treatments as planned. As in the case report, qualitative data (descriptions, photos, and videos) from immediate relatives and others suggested remarkable improvements in cognition and behavior. Moreover, there was no evidence of deterioration following LDIR in any of the cases. In addition, Case 3's daughter was so impressed with her father's improvement that she requested ongoing treatments for him. Surprisingly, there were few meaningful improvements on the three quantitative outcome measures.

Improvements in cognition and behavior were apparent within one day of treatment. Although the degree of recovery was relatively small, a therapy consisting of multiple treatments at the optimal dose, separated by the optimal time interval, may produce a much greater and long-lasting recovery from symptoms of AD. Figure 3 shows this concept-a large increase in the level of homeostasis that lasts for months [19, 29-31]. While the observations in

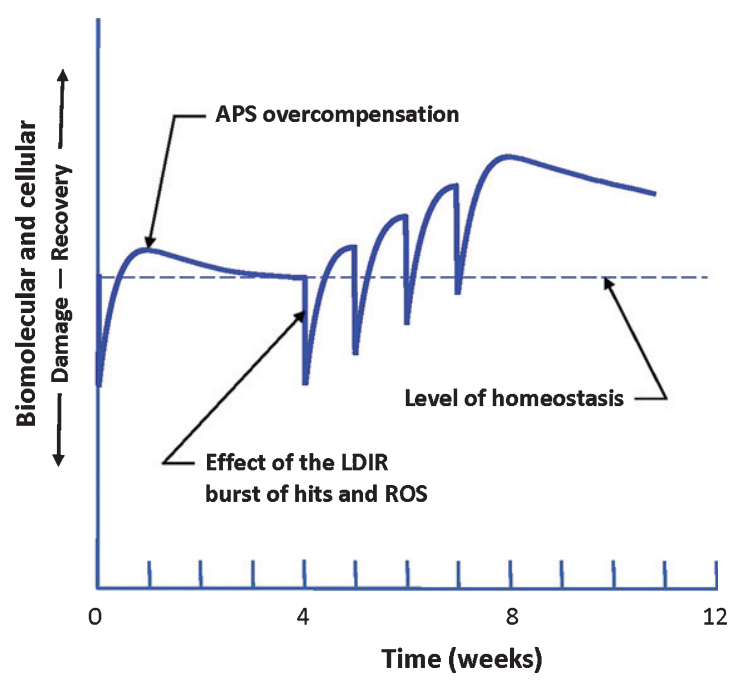

Fig. 3. Response of the patient to a burst of damage caused by an LDIR treatment. Repeated treatments result in a hypothesized strengthening of the performance of the adaptive protection systems (APS) as they adapt to repeated bursts of LDIR damage. These stronger systems produce some recovery from the buildup of endogenous oxidative damage that causes Alzheimer's disease. Their enhanced performance is expected to last for months [19, 29-31]. 
this small study support the underlying biological hypothesis for LDIR therapy, adequately powered double-blind placebo-controlled trials are required to determine the efficacy of this therapy and its limitations. Trials in participants with less advanced AD should also be considered. It is important to identify objective measures that are sensitive to the beneficial changes induced by LDIR treatments in severe cases of AD. The SIB, CMAI, and ADFACS measures were not sufficiently sensitive for patients with severe $\mathrm{AD}$, but remarkable qualitative changes were observed subjectively.

Objective, quantitative evidence in support of the underlying biological hypothesis for LDIR therapy was identified in the introduction, namely the study on transgenic mice deficient of DNA glycosylases that demonstrated X-ray-induced restoration of cognitive performance [22].

Future studies on LDIR therapy for AD should employ biological markers to objectively measure quantitative changes following each treatment. F2isoprostanes in cerebrospinal fluid have been found to be a good marker of oxidative stress that is associated with AD [32-34].

Although a CT scanner was used in this study to repeat treatments described in the previous case report [10], a simpler, less costly device may be appropriate for LDIR therapy of AD in future studies to deliver the desired radiation dose. Use of this device would allow treatments to be given in any hospital, eliminating the effect of transportation and change of environment on patient behavior.

Of the two doses applied, 80 and $40 \mathrm{mGy}$, a greater improvement was observed after the $80 \mathrm{mGy}$ treatment. It began to appear within hours and peaked in about 5 days. In future studies, doses from 50 to $500 \mathrm{mGy}$ should be assessed to determine the optimal dose and the optimal interval between treatments. These are expected to be the same for all humans; however, the amount of benefit will depend on individual genetics, age, and health status [29, 30]. Figure 1 in the cancer RT study by Tubiana et al. [35] suggests that a dose in the range from 100 to $500 \mathrm{mGy}$ may induce the optimal APS response. It also suggests that the threshold dose for the onset of adverse health effects is about 3 Gy.

Of 134 Chernobyl emergency workers who were heavily irradiated acutely, 28 died within several weeks. Biological dosimetry established they each received a dose above $5 \mathrm{~Gy}$. The 106 who recovered, in about one year, were studied for 30 years. They showed no evidence of radiation-induced delayed health effects, compared with unexposed workers [20]. This evidence suggests that the whole-body dose threshold for onset of long-term harm may be about 5 Gy. Patients with brain cancer may receive a whole brain dose of 30 Gy in 10 daily fractions of 3 Gy to "minimize early and late adverse effects of therapy [36]." The four clinical trials on LDIR therapy for $\mathrm{AD}$, mentioned in the introduction of this paper, will employ oncological RT to remove amyloid plaque. They will use daily fractions of $2 \mathrm{~Gy}$; three will give 5 treatments and one will give 10 treatments [3-6]. Success in these trials may lead to acceptance of LDIR therapy as a means for removing amyloid plaque in the brain and remediating $\mathrm{AD}$.

Limitations of this pilot study include small sample size, lack of a quantitative measure of improvement, lack of biological markers, lack of a placebo group, and open label design. Future research involving double-blind placebo-controlled trials using LDIR therapy are needed to demonstrate whether this is an effective therapy for AD. Biological markers of oxidative stress should be sampled as a measure of the response to LDIR treatment. In this study, we selected clinically stable cases with severe AD. This may have limited the effects of LDIR treatment. It may thus be beneficial for future studies to include patients with milder disease.

In conclusion, this pilot study indicates that LDIR may be a promising therapy for AD. Moreover, the rationale for this therapy, stimulation of innate adaptive protection systems against oxidative distress, suggests it might be effective in treating other neurodegenerative diseases.

\section{ACKNOWLEDGMENTS}

We are grateful to the patients who participated in this study, as well as their family members. We acknowledge the excellent support from CT Charge Technologist Mike Minoo, at Sunnybrook Health Sciences Centre, who was helpful in setting up the scanning protocol and scanning the subjects. Dr. Freedman received supports from the Saul A. Silverman Family Foundation as a Canada International Scientific Exchange Program (MF), and Morris Kerzner Memorial Fund.

Authors' disclosures available online (https:// www.j-alz.com/manuscript-disclosures/20-0620r3). 


\section{SUPPLEMENTARY MATERIAL}

The supplementary material is available in the electronic version of this article: https://dx.doi.org/ 10.3233/JAD-200620.

\section{REFERENCES}

[1] Wolk DA, Dickerson BC (2018) Clinical features and diagnosis of Alzheimer disease. UpToDate. https://www. uptodate.com/contents/clinical-features-and-diagnosis-ofalzheimer-disease

[2] Michael DB, Wilson GD, Hanna A, Wilson T, Martinez AA, Chinnalyan P, Maddens ME, Fontanesi J (2019) Radiation therapy for the treatment of Alzheimer's disease. Neuro Neurosurg 2, 1-6.

[3] Harris TJ (2016) Phase IIa trial of low dose radiation therapy to reduce cerebral amyloidosis in early Alzheimer's dementia. ClinicalTrials.gov PRS. NCT02769000.

[4] Chung WK (2019) The safety and scientific validity of lowdose whole brain radiotherapy on brain amyloidosis during the treatment of mild or moderate Alzheimer's disease. ClinicalTrials.gov PRS. NCT04203121.

[5] Zilli T (2017) Effect of low dose radiotherapy on brain amyloidosis in the treatment of Alzheimer's disease: A randomized pilot study. ClinicalTrials.gov PRS. NCT 03352258 .

[6] Fontanesi J (2019) Phase I feasibility study of low dose whole brain irradiation in the treatment of Alzheimer's disease. ClinicalTrials.gov PRS. NCT02359864.

[7] Ceyzeriat K, Tournier BB, Miller P, Frisoni GB, Garibotto V, Zilli T (2020) Low-dose radiation therapy: A new treatment strategy for Alzheimer's disease? J Alzheimers Dis 74, 411419.

[8] Kim S, Nam Y, Kim C, Lee H, Hong S, Kim HS, Shin SJ, Park YH, Mai HN, Oh S-M, Kim KS, Yoo D-H, Chung WK, Chung H, Moon M (2020) Neuroprotective and anti-inflammatory effects of low-moderate dose ionizing radiation in models of Alzheimer's disease. Int $\mathrm{J} \mathrm{Mol}$ Sci 21, 3678.

[9] Kim S, Chung H, Mai HN, Nam Y, Shin SJ, Park YH, Chung MJ, Lee JK, Rhee HY, Jahng G-H, Kim Y, Lim YJ, Kong M, Moon M, Chung WK (2020) Low-dose ionizing radiation modulates microglia phenotypes in the models of Alzheimer's disease. Int J Mol Sci 21, 4532.

[10] Cuttler JM, Moore ER, Hosfeld VD, Nadolski DL (2016) Treatment of Alzheimer disease with CT scans: A case report. Dose Response 14, 1-7.

[11] Cuttler JM, Moore ER, Hosfeld VD, Nadolski DL (2017) Letter to the Editor. Update on a patient with Alzheimer disease treated with CT scans. Dose Response 15, 1-2.

[12] Cuttler JM, Moore ER, Hosfeld VD, Nadolski DL (2018) Letter to the Editor. Second update on a patient with Alzheimer disease treated by CT scans. Dose Response 16, $1-2$.

[13] Pollycove M, Feinendegen LE (2003) Radiation-induced versus endogenous DNA damage: Possible effect of inducible protective responses in mitigating endogenous damage. Hum Exp Toxicol 22, 290-306.

[14] Ma MW, Wang J, Zhang Q, Wang, R, Dhandapani KM, Vadlamudi RK, Brann DW (2017) NADPH oxidase in brain injury and neurodegenerative disorders. Mol Neurodegener 12,7 .
[15] Sies H, Jones DP (2020) Reactive oxygen species (ROS) as pleiotropic physiological signalling agents. Nat Rev Mol Cell Biol 21, 363-383.

[16] Go Y-M, Jones DP (2017) Redox theory of aging: Implications for health and disease. Clin Sci (Lond) 131, 1669-1688.

[17] Sies H, Berndt C, Jones DP (2017) Oxidative stress. Ann Rev Biochem 86, 715-748.

[18] Mailloux RJ (2020) An update on mitochondrial reactive oxygen species production. Antioxidants 9, 472 .

[19] Feinendegen LE, Cuttler JM (2018) Biological effects from low doses and dose rates of ionizing radiation: Science in the service of protecting humans: A synopsis. Health Physics 114, 623-626.

[20] Cuttler JM (2020) Application of low doses of ionizing radiation in medical therapies. Dose Response 18, $1-17$.

[21] Sies H, Feinendegen LE (2017) Radiation hormesis: The link to nanomolar hydrogen peroxide. Antioxid Redox Signal 27, 596-598.

[22] Hofer T, Duale N, Muusse M, Eide DM, Dahl H, Boix F, Anderson JM, Olsen AK, Myhre O (2018) Restoration of cognitive performance in mice carrying a deficient allele of 8-oxoguanine DNA glycosylase by X-ray irradiation. Neurotox Res 33, 824-836.

[23] Al-Shamaa S (2018) Low dose ionizing radiation using CT scans as a potential therapy for Alzheimer's dementia (LDIR-CT-AD) trial: A pilot study. ClinicalTrials. gov PRS. NCT03597360.

[24] Department of Radiology, University of California Davis Health System. Radiation dose reporting. http://www. ucdmc.ucdavis.edu/radiology/radiationdose.html

[25] Jack CR, Albert MS, Knopman DS, McKhann GM, Sperling RA, Carrillo MC, Thies B, Phelps CH (2011) Introduction to the recommendations from the National Institute on Aging-Alzheimer's Association workgroups on diagnostic guidelines for Alzheimer's disease. Alzheimers Dement 7, 257-262.

[26] Panisset M, Roudier M, Saxton J, Boller F (1994) Severe impairment battery: A neuropsychological test for severely demented patients. Arch Neurol 51, 41-45.

[27] Cohen-Mansfield J, Marx MS, Rosenthal AS (1989) A description of agitation in a nursing home. $J$ Gerontol Med Sci 44, M77-M84.

[28] Manero RM, Casals-Coll M, Sánchez-Benavides G, Rod ríguez-de los Reyes ON, Aguilar M, Badenes D, Molinuevo JL, Robles A, Barquero MS, Antúnez C, Martínez-Parra C, Frank-García A, Fernández M, Blesa R, Peña-Casanova J (2014) Diagnostic validity of the Alzheimer's disease functional assessment and change scale in mild cognitive impairment and mild to moderate Alzheimer's disease. Dement Geriatr Cogn Disord 37, 366-375.

[29] Feinendegen LE, Pollycove M, Neumann RD (2007) Whole-body responses to low-level radiation exposure: New concepts in mammalian radiobiology. Exp Hematol 35, $37-46$.

[30] Feinendegen LE (2016) Quantification of adaptive protection following low-dose irradiation. Health Physics 110, 276-280.

[31] Pollycove M (2007) Radiobiological basis of low-dose irradiation in prevention and therapy of cancer. Dose Response 5, 1-13.

[32] Lindqvist D, Dhabhar FS, James SJ, Hough CM, Jain FA, Bersani FS, Reus VI, Verhoeven JE, Epel ES, Mahan L, Rosser R, Wolkowitz OM, Mellon SH (2017) Oxida- 
tive stress, inflammation and treatment response in major depression. Psychoneuroendocrinology 76, 197-205.

[33] Montine TJ, Montine KS, McMahan W, Markesbery WR, Quinn JF, Morrow JD (2005) F2-isoprostanes in Alzheimer and other neurodegenerative diseases. Antioxid Redox Signal 7, 269-275.

[34] Kuo H-C, Yen H-C, Huang C-C, Hsu W-C, Wei HJ, Lin C-L (2015) Cerebrospinal fluid biomarkers for neuropsychological symptoms in early stage of late-onset Alzheimer's disease. Int J Neurosci 125, 747-754.
[35] Tubiana M, Diallo I, Chavaudra J, Lefkopoulos D, Bourhis J, Girinsky T, Brider A, Hawkins M, Haddy N, El-Fayech C, Adjadj E, Clero E, de Vathaire F (2011) A new method of assessing the dose-carcinogenic effect relationship in patients exposed to ionizing radiation, a concise presentation of preliminary data. Health Phys 100, 296-299.

[36] Loeffler JS (2020) Overview of the treatment of brain metastases. UpToDate. https://www.uptodate.com/contents/ove rview-of-the-treatment-of-brain-metastases 